\title{
Effect of aqueous herbal extracts on growth, plasma metabolites and meat characteristics of broiler
}

\author{
MLY Camy ${ }^{1}$, MRA Redoy ${ }^{1}$, AAS Shuvo ${ }^{1}$, BC Ray ${ }^{2}$, MA Rahman ${ }^{1}$ and M Al-Mamun ${ }^{1 *}$ \\ ${ }^{1}$ Department of Animal Nutrition, Bangladesh Agricultural University, Mymensingh-2202, Bangladesh; \\ ${ }^{2}$ Department of Poultry Science, Bangladesh Agricultural University, Mymensingh-2202, Bangladesh
}

\begin{abstract}
The experiment was carried out for 4 weeks to find out the efficacy of herbal extracts supplementation in drinking water on production performance, plasma metabolites, carcass characteristics, and fat deposition of commercial broilers. A total of 200 straight run day-old chicks (Cobb-500) were divided into five treatment groups; $T_{0}=$ Basal diet, $T_{1}=$ Basal diet $+10 \mathrm{ppm}$ neem leaves extract, $\mathrm{T}_{2}=$ Basal diet+10 ppm garlic leaves extract, $T_{3}=$ Basal diet $+10 \mathrm{ppm}$ plantain leaves extract, $T_{4}=$ Basal diet +10 ppm antibiotic growth promoter (AGP) each with four replications having 10 birds per replicate. All the herbal extracts and AGP were supplemented in drinking water. Ration in the form of crumble was offered to the birds ad libitum having $M E=3060 \mathrm{kcal} / \mathrm{kg}$ and $\mathrm{CP}=22.5 \%$. Body weight and feed intake were recorded weekly to calculate body weight gain (BWG) and feed conversion ratio (FCR). A total of 15 birds three from each treatment were sacrificed at the end of feeding trial and dressing parameters were evaluated. Sensory properties of broiler meat were assessed by a panel of experts. Feed intake, BWG and FCR varied $(p<0.05)$ in all treated groups, and the higher BWG and improved FCR were found in AGP group. Triglyceride and very low-density lipoprotein content were lower $(p<0.05)$ in all herbal treated groups than the control and elevated at AGP group. However, increased $(p<0.001)$ dressing percentage and abdominal fat deposition were found in AGP group compared to herbal treated groups and the least value was found in plantain group which also exhibited lower $(p<0.001)$ meat ether extract. Flavor $(p=0.001)$, juiciness $(p=0.002)$, tenderness $(p=0.005)$ and overall acceptability $(p<0.001)$ of broiler meat were significantly higher in herbal group over control and AGP group. The aqueous herbal extract supplementation could be an alternative to antibiotic growth promoter to enhance growth performance, plasma lipid profiles as well as to reduce abdominal fat and meat of either extract.
\end{abstract}

Key words: broiler, herbal extracts, blood lipid profile, abdominal fat, sensory test

Bangladesh Animal Husbandry Association. All rights reserved.

Bang. J. Anim. Sci. 2019. 48 (2):108-115

\section{Introduction}

Feed additives are added to poultry feed for improving nutritive value of ingredients and enhancing broiler performance by increasing growth rate and improving feed conversion efficiency. Chemical feed additives e.g. antibiotic growth promoters (AGP) have long been intensively used in broiler ration to improve productivity. Antibiotic growth promoters are used to help growing animals to utilize their feed efficiently, get maximum benefit from it and allow them to become strong and healthy (Miles et al., 2006). Although the mechanism supporting their action is unclear, it is believed that the antibiotics suppress sensitive populations of bacteria in the intestines. Thomke and Elwinger (1998) hypothesized that cytokines released during the immune response may also stimulate the release of catabolic hormones, which would reduce muscle mass. Therefore, a reduction in gastrointestinal infections would result in the subsequent increase in muscle weight. Whatever the mechanism of action, the result of the use of growth promoters is an improvement in daily growth rates between 1 and 10 percent resulting in meat of a better quality, with less fat and increased protein content.

However, they are notorious for bacterial resistance and their negative impacts on the consumers' health. Thus, use of AGP has been banned in poultry industry. There is evidence that resistance in some human enteric pathogens has arisen because of transfer of resistant bacteria or resistance genes from animals to people via the food chain (Barton, 2000; Roe and Pillai, 2003). Indiscriminate use 


\section{Herbal extracts in broiler production}

of antibiotic growth promoters (AGPs) as subtherapeutic level in animals and poultry caused consequent appearance of resistance to that particular antibiotic among several pathogenic bacteria (Rerksuppaphol et al., 2003 and Zhao et al., 2003). Cervantes (2004) stated that scientific evidence of antibiotic resistance in food animals is associated with resistance infections in humans. Some scientists believe dependence on and misuse of antibiotics in human medicine is the primary cause of resistance. It has been postulated that reexposure to previously withdrawn antibiotics will lead to a rebound effect, with very rapid reemergence of resistance (Salyers and AmabileCuevas, 1997). The possible adverse effect of using antibiotics to human health was first reported by Swann (1969). It was mentioned that the probable hazard to human health was from feeding sub-therapeutic levels of antibiotics to food producing animals. Antibiotic resistance genes may be transferred from animal pathogens or commensals to human pathogens (Miles et al., 2006). Gold and Moellering (1996) stated that the majority of human antibiotic resistance problems have connection with use of antibiotics in animals. Several reports (WHO, 1998 and MAFF, 1998) described the link between antibiotic use in animals and the development of resistance in human pathogens.

Considering adverse effect and withdrawal of antibiotic growth promoters by EU, scientists are actively looking for an efficacious alternative to AGPs. Different herbal extracts containing bioactive components have the compatibility. Various herbal products are being used as growth promoters in the poultry rations like garlic leaves (Ahmad, 2005), kalongi (Ihsan, 2003), plantain (Plantago lanceolate L.) which have anti-oxidative activity (Wang et al., 1996) and anti-inflammatory effects (Marchesan et al., 1998), neem leaves rich in nimbin that have free radical scavenging activity. This experiment was designed to find out suitable herbal extract for broiler that might be compatible with AGP.

\section{Materials and Methods}

\section{Experimental birds and management}

The experiment was conducted in a poultry rearing unit at Shahjalal Animal Nutrition Field Laboratory, Bangladesh Agricultural University, Mymensingh for a period of 28 days. Two hundred straight run day-old broiler chicks (Cobb-500) were purchased from a commercial hatchery and divided into five treatment groups ( $\mathrm{T} 0=$ Control group, $\mathrm{T} 1=$ Neem group, $\mathrm{T} 2=$ Garlic group, T3= Plantain group, T4= Antibiotic growth promoter group) with four replications per treatment having 10 birds in each replication. Continuous lighting was provided throughout the experiment. The brooding temperature was maintained $32^{\circ} \mathrm{C}$ in $1^{\text {st }}$ week and thereafter gradually decreased $3^{\circ} \mathrm{C}$ in each week until it reached to $21^{\circ} \mathrm{C}$. A completely randomized design was used involving five dietary treatments and four replicates for each. Plantain, garlic and neem was cultivated at Shahjalal Animal Nutrition Field and Quinosol $10 \%$ was used as an antibiotic growth promoter. The Ingredients composition and chemical constituents of basal diet are presented in Table 1.

Table 1: Composition and chemical constituents of ration

\begin{tabular}{lc}
\hline Ingredients & Amount \\
\hline Maize (\%) & 51.50 \\
Rice Polish (\%) & 2.00 \\
Protein concentrate (\%) & 6.05 \\
Soybean oil (\%) & 4.00 \\
Soybean meal (\%) & 26.50 \\
Mustard oil cake (\%) & 3.80 \\
Di- calcium phosphate (\%) & 1.35 \\
Meat and bone meal (\%) & 4.00 \\
Vit-mineral premix (\%) & 0.25 \\
Methionine (\%) & 0.05 \\
Common salt (\%) & 0.50 \\
Chemical Constituents (g/100g DM) & \\
Dry matter & 89.00 \\
Crude protein & 22.50 \\
Crude fibre & 5.00 \\
Ether extract & 4.00 \\
Nitrogen free extract & 48.61 \\
Ash & 8.39 \\
Calcium & 0.84 \\
Phosphorus & 0.56 \\
\hline
\end{tabular}

*Each $\mathrm{kg}$ premix contained: vitamin A palmitate, 6,600 IU; cholecalciferol, 2,200 IU; menadione dimethylpyridine bisulfite, $2.2 \mathrm{mg}$; riboflavin, $4.4 \mathrm{mg}$; pantothenic acid, $13 \mathrm{mg}$; niacin, $40 \mathrm{mg}$; choline chloride $500 \mathrm{mg}$; biotin, $1 \mathrm{mg}$; vitamin B12, $22 \mu \mathrm{g}$; ethoxyquin, $125 \mathrm{mg}$; iron, $50 \mathrm{mg}$; copper, $6 \mathrm{mg}$; zinc, $40 \mathrm{mg}$; manganese, $60 \mathrm{mg}$; selenium, $0.2 \mathrm{mg}$. 
Camy et al. (2019) Bang. J. Anim. Sci. 48 (2):108-115

Fresh neem leaves, garlic leaves and plantain leaves were harvested at $5 \mathrm{~cm}$ above ground level, placed in a polyethylene bag and dried at $-30^{\circ} \mathrm{C}$ by using a vacuum freeze dryer (FRD50M; Iwaki Glass, Tokyo, Japan) in order to minimize any unwanted changes of bioactive components by oxidation. Then $10 \mathrm{mg}$ dried sample was mixed with 1-liter drinking water to prepare $10 \mathrm{ppm}$ herbal extract and served to birds twice a day. Feed consumption was recorded weekly basis, by recording the feed offered and amounts retained in feeders at end of each week. Individual bird weight was also recorded weekly.

\section{Sample collection and analysis}

The proximate components of feeds and meat were analyzed according to AOAC (1990). Blood samples ( $5 \mathrm{ml}$ each) were collected on day 28 of the feeding trial in a heparinized tube and kept in an ice box until centrifugation. Samples were centrifuged at $10000 \times \mathrm{g}$ at $4^{\circ} \mathrm{C}$ for 10 minutes for plasma separation and plasma was stored at $-20^{\circ} \mathrm{C}$. Plasma metabolites were analyzed using spectrophotometer (Spectronic, Genesis 5, USA) for determining the total cholesterol, triglycerides, LDL-cholesterol, HDLcholesterol, VLDL-cholesterol against the blank reagent at $510 \mathrm{~nm}$ wave length by using different kits.

\section{Statistical Analysis}

Analysis of variance was used to test the significance of treatment effects. Differences among treatment means were tested using Tukey's HSD test with a significance level of 0.05 or better. Carcass and visceral organ variables were expressed as percentages of live weights. These analyses were performed using SPSS statistical analysis software (SPSS Inc., Chicago, IL, USA).

\section{Results and Discussion}

\section{Growth performance}

Supplementation of different herbal extracts with drinking water influenced growth performances of commercial broilers significantly (Table 2). Higher feed intake (3.3$5.2 \%$ ) was recorded in the treated groups (neem, garlic and plantain) except for antibiotic growth promoter (AGP) over control. Enhanced weight gain in relation to control group $(p<0.001)$ resulted due to inclusion of herbal extracts and AGP. Feed intake in neem, garlic and plantain treated groups was higher $(p=0.003)$ whereas it did not affect the feed conversion ratio (FCR). However, AGP treated group exerted better FCR compared to control which was indifferent with neem and plantain treated groups. Present experiment revealed that supplementation of herbal extracts improved weight gain and feed efficiency of broilers that was compatible with antibiotic growth promoter (AGP). Our result was in agreement with the findings of different researchers who reported that higher weight gain and improved FCR in broilers when drinking water was supplemented with neem leaves extracts (Sarker et al., 2014, Wankar et al., 2009), garlic leaves (Meraj el al., 1998), plantain (Chacrabarti et al., 2013). The enhanced weight gain might be due to the presence of different bioactive components in herbal extract like allicin in garlic leaves (Martin et al., 2016), nimbin in neem leaves (Sultana et al., 2007), catalpol, aucubin, acteosides in plantain (Al-Mamun et al., 2008). These bioactive components have bactericidal (Gordon and Wareham, 2010), and bacteriostatic properties (Etxeberria et al., 2013) and they minimize the adhesion of pathogenic bacteria (E. coli, Clostridium), inhibit the progression of infections in the digestive tract, thus improve nutrient utilization and performance.

Table 2: Production performance of broilers at 28 days at different dietary treatment

\begin{tabular}{lrrrrrr}
\hline Parameters & \multicolumn{1}{c}{$\mathbf{T}_{\mathbf{0}}$} & \multicolumn{1}{c}{$\mathbf{T}_{\mathbf{1}}$} & \multicolumn{1}{c}{$\mathbf{T}_{\mathbf{2}}$} & \multicolumn{1}{c}{$\mathbf{T}_{\mathbf{3}}$} & \multicolumn{1}{c}{$\mathbf{T}_{\mathbf{4}}$} & \multicolumn{1}{c}{ p-value } \\
\hline Initial weight (g) & $44 \pm 0.6$ & $43 \pm 1.1$ & $44 \pm 0.9$ & $43 \pm 0.5$ & $44 \pm 0.7$ & 0.16 \\
Final weight (g) & $1095^{\mathrm{b}} \pm 5$ & $1153^{\mathrm{a}} \pm 4$ & $1144^{\mathrm{a}} \pm 4$ & $1170^{\mathrm{a}} \pm 4$ & $1181^{\mathrm{a}} \pm 6$ & $<0.001$ \\
Weight gain (g) & $1051^{\mathrm{b}} \pm 6$ & $1110^{\mathrm{a}} \pm 26$ & $1100^{\mathrm{a}} \pm 12$ & $1127^{\mathrm{a}} \pm 17$ & $1137^{\mathrm{a}} \pm 20$ & $<0.001$ \\
Feed intake (g) & $1783^{\mathrm{b}} \pm 5$ & $1842^{\mathrm{a}} \pm 8$ & $1848^{\mathrm{a}} \pm 42$ & $1874^{\mathrm{a}} \pm 33$ & $1829^{\mathrm{ab}} \pm 16$ & 0.003 \\
FCR (feed:gain) & $1.69^{\mathrm{a}} \pm 0.01$ & $1.65^{\mathrm{ab}} \pm 0.03$ & $1.68^{\mathrm{a}} \pm 0.03$ & $1.66^{\mathrm{ab}} \pm 0.02$ & $1.61^{\mathrm{b}} \pm 0.02$ & 0.004 \\
\hline
\end{tabular}

Means with similar superscript in the same row differ significantly; FCR-feed conversion ratio. $\mathrm{T}_{0}$-No supplementation in drinking water; $T_{1}$ - Neem leaves extract supplementation $(10 \mathrm{ppm})$ in drinking water; $\mathrm{T}_{2}-$ Garlic leaves extract supplementation $(10 \mathrm{ppm})$ in drinking water; $\mathrm{T}_{3}$ - Plantain extract supplementation (10 $\mathrm{ppm}$ ) in drinking water; $\mathrm{T}_{4}$-Quinosol $10 \%$ supplementation (10 ppm) in drinking water. 


\section{Plasma metabolites}

Herbal extract supplementation with drinking water did not show any positive impact on total cholesterol, high density lipoprotein and lowdensity lipoprotein contents in experimental birds. Triglyceride and very low-density lipoprotein contents were lower $(p<0.05)$ in all the herbal treated groups than control but elevated at AGP group.

Several studies (Aouadi et al., 2000; Yeh and Liu, 2001) reported cholesterol lowering effect with the addition of garlic leaves in broiler, which is contradictory with our findings. Moreover, Konjufca et al. (1997) noted that garlic leaves powder had significant effect on reduction of plasma triacylglycerols (TGs) in broiler. Likewise, Chowdhury et al. (2002) found lower TGs content in layer eggs supplemented with $2 \%$ garlic powder in basal diet and Choi et al. (2010) also found lower serum TGs in broiler fed dried garlic leaves. Issa and Omar (2012) investigated that garlic leaves powder decreased triglyceride, LDL and increased HDL levels compared to control in broiler that justify our findings. Main reason for reducing TGs content in our experiment might be due to garlic supplementation decreased 3hydroxy-3-methylglutaryl reductase activity and cholesterol 7 alpha-hydroxylase activity (Konjufca et al., 1997) and ultimately it reduced the TGs content in garlic leaves supplemented group.

\section{Carcass characteristics}

Higher abdominal fat content $(p<0.001)$ was obtained in the AGP group. Plantain and garlic leaves extracts exhibited reduction of abdominal fat compared to control whereas no change $(p>0.05)$ was found in birds supplemented with neem leaves extract. Highest breast meat was found in control group over all the treated groups, but among the treated groups, the proportion was higher in herbal extract groups compared to AGP treated group. Drumstick and thigh muscle percentage were comparatively higher in plantain group, whereas liver content was highest in AGP group. Dressing percent in all the treated groups was higher except for garlic, which was similar to control. No significant variation was depicted in other parameters.

Neem leaves (Grela and Klebaniuk, 2007), garlic leaves (Thampi and Jeyadoss, 2015) and plantain (Al- Mamun et al., 2008) are not only the sources of bioactive components but also good sources of proteins and minerals (AlMamun et al., 2007), which cause higher protein retention and availability leading to better performance and yielded carcass in broiler. Acteoside that are present in plantain (Al-Mamun et al., 2007) stimulates leptin expression and cholesterol catabolism, suppressing fatty acid synthesis, and accelerating fatty acid $\beta$-oxidation(Yang et al., 2017) and this is one of the reasons for getting lower fat content in plantain supplemented group. Chacrabarti et al. (2013) observed positive effects of Plantago major L. on carcass characteristics of broiler. Garlic leaves contain a higher concentration of sulfur containing bioactive component like alliin, allicin, Sallylcysteine, diallydisulphide (Onu, 2010) that also behave like acteoside and stimulates leptin expression and cholesterol catabolism.

Table 3: Plasma metabolites of broilers in different dietary treatments

\begin{tabular}{lcccccc}
\hline Parameters & $\mathbf{T}_{\mathbf{0}}$ & $\mathbf{T}_{\mathbf{1}}$ & $\mathbf{T}_{\mathbf{2}}$ & $\mathbf{T}_{\mathbf{3}}$ & $\mathbf{T}_{\mathbf{4}}$ & p-value \\
\hline TGs $(\mathrm{mg} / \mathrm{dl})$ & $61.27^{\mathrm{ab}} \pm 1.95$ & $55.11^{\mathrm{ab}} \pm 1.63$ & $54.43^{\mathrm{b}} \pm 1.85$ & $58.54^{\mathrm{ab}} \pm 3.17$ & $65.57^{\mathrm{a}} \pm 3.89$ & 0.037 \\
Cholesterol & $86.45 \pm 1.28$ & $82.60 \pm 1.32$ & $81.33 \pm 1.51$ & $80.98 \pm 3.30$ & $88.73 \pm 2.97$ & 0.063 \\
(mg/dl) & & & & & & \\
HDL- C (mg/dl) & $53.34 \pm 2.90$ & $51.56 \pm 2.43$ & $50.79 \pm 3.44$ & $50.30 \pm 2.88$ & $56.48 \pm 2.64$ & 0.324 \\
LDL-C (mg/dl) & $20.85 \pm 2.01$ & $20.01 \pm 3.41$ & $19.65 \pm 2.30$ & $18.99 \pm 2.73$ & $19.13 \pm 2.0$ & 0.942 \\
VLDL-C (mg/dl) & $12.25^{\mathrm{ab}} \pm 0.39$ & $11.02^{\mathrm{ab}} \pm 0.32$ & $10.88^{\mathrm{b}} \pm 0.37$ & $11.69^{\mathrm{ab}} \pm 0.63$ & $13.11^{\mathrm{a}} \pm 0.77$ & 0.037 \\
\hline
\end{tabular}

Means with similar superscript in the same row differ significantly; TGs, triglycerides; HDL, high density lipoprotein; LDL, low density lipoprotein; VLDL, very low-density lipoprotein. $\mathrm{T}_{0}$ - No supplementation in drinking water; $T_{1}$ - Neem leaves extract supplementation $(10 \mathrm{ppm})$ in drinking water; $\mathrm{T}_{2}$ - Garlic leaves extract supplementation $(10 \mathrm{ppm})$ in drinking water; $\mathrm{T}_{3}$ - Plantain extract supplementation $(10 \mathrm{ppm})$ in drinking water; $\mathrm{T}_{4}$ - Quinosol $10 \%$ supplementation (10 ppm) in drinking water. 
Camy et al. (2019) Bang. J. Anim. Sci. 48 (2):108-115

Table 4: Carcass characteristics of broiler in different dietary treatments

\begin{tabular}{lrrrrrr}
\hline Parameters & \multicolumn{1}{c}{$\mathbf{T}_{\mathbf{0}}$} & \multicolumn{1}{c}{$\mathbf{T}_{\mathbf{1}}$} & \multicolumn{1}{c}{$\mathbf{T}_{\mathbf{2}}$} & $\mathbf{T}_{\mathbf{3}}$ & \multicolumn{1}{c}{$\mathbf{T}_{\mathbf{4}}$} & \multicolumn{1}{c}{ p-value } \\
\hline Head (\%) & 3.08 & 2.83 & 3.23 & 3.18 & 3.13 & 0.200 \\
Neck (\%) & 2.79 & 2.80 & 2.75 & 3.13 & 2.89 & 0.085 \\
Breast (\%) & $18.58^{\mathrm{a}}$ & $18.38^{\mathrm{b}}$ & $16.51^{\mathrm{d}}$ & $17.07^{\mathrm{c}}$ & $16.5^{\mathrm{d}}$ & $<0.001$ \\
Drumstick (\%) & $4.23^{\mathrm{b}}$ & $4.29^{\mathrm{b}}$ & $4.26^{\mathrm{b}}$ & $4.53^{\mathrm{a}}$ & $4.09^{\mathrm{c}}$ & $<0.001$ \\
Thigh (\%) & $7.81^{\mathrm{c}}$ & $8.27^{\mathrm{a}}$ & $7.91^{\mathrm{b}}$ & $8.33^{\mathrm{a}}$ & $8.29^{\mathrm{a}}$ & $<0.001$ \\
Shank (\%) & 4.56 & 4.74 & 4.79 & 4.60 & 4.36 & 0.112 \\
Heart (\%) & 0.61 & 0.64 & 0.63 & 0.74 & 0.65 & 0.217 \\
Liver (\%) & $3.39^{\mathrm{c}}$ & $3.22^{\mathrm{d}}$ & $3.63^{\mathrm{b}}$ & $3.67^{\mathrm{b}}$ & $3.92^{\mathrm{a}}$ & $<0.001$ \\
Kidney (\%) & 0.23 & 0.22 & 0.17 & 0.18 & 0.20 & 0.133 \\
Gizzard (\%) & 3.13 & 2.89 & 2.74 & 2.87 & 2.94 & 0.092 \\
Viscera (\%) & 7.38 & 7.52 & 8.09 & 7.35 & 7.69 & 0.125 \\
Abdominal fat (\%) & $1.33^{\mathrm{b}}$ & $1.35^{\mathrm{b}}$ & $1.25^{\mathrm{b}}$ & $1.15^{\mathrm{c}}$ & $2.01^{\mathrm{a}}$ & $<0.001$ \\
Blood (\%) & 3.31 & 3.33 & 4.13 & 3.19 & 3.51 & 0.111 \\
Skin (\%) & 5.43 & 7.21 & 8.18 & 7.21 & 7.68 & 0.075 \\
Feather (\%) & 8.26 & 7.01 & 6.65 & 7.27 & 6.93 & 0.225 \\
DP (\%) & $60.73^{\mathrm{c}}$ & $61.56^{\mathrm{b}}$ & $60.83^{\mathrm{c}}$ & $61.50^{\mathrm{b}}$ & $63.52^{\mathrm{a}}$ & $<0.001$ \\
\hline
\end{tabular}

Mean with similar superscript in the same row differ significantly; $D P$, Dressing percentage. $T_{0}-N^{-}$ supplementation in drinking water; $T_{1}$ - Neem leaves extract supplementation $(10 \mathrm{ppm})$ in drinking water; $\mathrm{T}_{2^{-}}$ Garlic leaves extract supplementation $(10 \mathrm{ppm})$ in drinking water; $\mathrm{T}_{3}$ - Plantain extract supplementation (10 $\mathrm{ppm}$ ) in drinking water; $\mathrm{T}_{4}$ - Quinosol $10 \%$ supplementation $(10 \mathrm{ppm})$ in drinking water

Table 5: Proximate composition of broiler meat in different dietary treatments

\begin{tabular}{lrrrrrr}
\hline Parameters & \multicolumn{1}{c}{$\mathbf{T}_{\mathbf{0}}$} & \multicolumn{1}{c}{$\mathbf{T}_{\mathbf{1}}$} & \multicolumn{1}{c}{$\mathbf{T}_{\mathbf{2}}$} & \multicolumn{1}{c}{$\mathbf{T}_{\mathbf{3}}$} & $\mathbf{T}_{\mathbf{4}}$ & P-value \\
\hline Moisture (\%) & $74.36 \pm 0.86$ & $72.68 \pm 1.25$ & $73.70 \pm 1.11$ & $74.04 \pm 2.01$ & $73.97 \pm 0.33$ & 0.545 \\
CP (\%) & $22.38 \pm 0.77$ & $22.66 \pm 1.15$ & $22.90 \pm 0.35$ & $22.47 \pm 0.58$ & $22.35 \pm 1.01$ & 0.912 \\
CF (\%) & $0.69 \pm 0.04$ & $0.61 \pm 0.04$ & $0.74 \pm 0.07$ & $0.65 \pm 0.21$ & $0.67 \pm 0.14$ & 0.765 \\
EE (\%) & $1.87^{\mathrm{a}} \pm 0.11$ & $1.42^{\mathrm{b}} \pm 0.12$ & $1.39^{\mathrm{b}} \pm 0.14$ & $1.36^{\mathrm{b}} \pm 0.08$ & $2.08^{\mathrm{a}} \pm 0.79$ & $<0.001$ \\
NFE (\%) & $73.84 \pm 0.84$ & $74.10 \pm 1.31$ & $73.80 \pm 0.32$ & $74.41 \pm 0.65$ & $73.76 \pm 0.86$ & 0.867 \\
Ash (\%) & $1.2 \pm 0.09$ & $1.21 \pm 0.036$ & $1.16 \pm 0.07$ & $1.09 \pm 0.05$ & $1.12 \pm 0.08$ & 0.374 \\
\hline
\end{tabular}

Mean with similar superscript in the same row differ significantly; $C P$, crude protein; $C F$, crude fibre; $E E$, ether extract; NFE, nitrogen free extract. $\mathrm{T}_{0}$ - No supplementation in drinking water; $\mathrm{T}_{1}$ - Neem leaves extract supplementation (10 ppm) in drinking water; $\mathrm{T}_{2}-$ Garlic leaves extract supplementation (10 ppm) in drinking water; $\mathrm{T}_{3}$ - Plantain extract supplementation $(10 \mathrm{ppm})$ in drinking water; $\mathrm{T}_{4^{-}}$Quinosol $10 \%$ supplementation $(10 \mathrm{ppm})$ in drinking water

\section{Meat composition}

Proximate components of meat from different dietary treatments did not show any statistical variation except ether extract (EE). Herbal extract supplementation exhibited the positive impact on lean meat production (Table 5). Higher EE was found in both AGP and control groups. However, there was no variation $(p<0.05)$ in meat EE content among the herbal treated groups. Herbal extract like neem leaves (Choudhary et al., 2011), garlic leaves (Thampi and Jeyadoss, 2015), and plantain (Al-Mamun et al., 2008a) acts as a strong superoxide anion scavenger and natural antioxidant. Antioxidant prevents auto oxidation in the body for which fat is reduced. Chacrabati et al. (2013) found 
similar result with plantain herbs as a replacement of commercial antioxidant in broiler feed. Dey et al. (2012) found lower serum cholesterol in neem leaves fed laying pullet which also justify our findings. On the contrary, several investigations suggested no significant effect on major carcass components and meat characteristics (Javandel et al., 2008; Onibi et al., 2009; Raeesi et al., 2010) which contradicted our findings. On the other hand, Rahimi et al. (2011) found positive result especially lower fat content in broiler meat with different herbal extracts like neem, nishyinda and papaya compared to antibiotics virginiamycin.

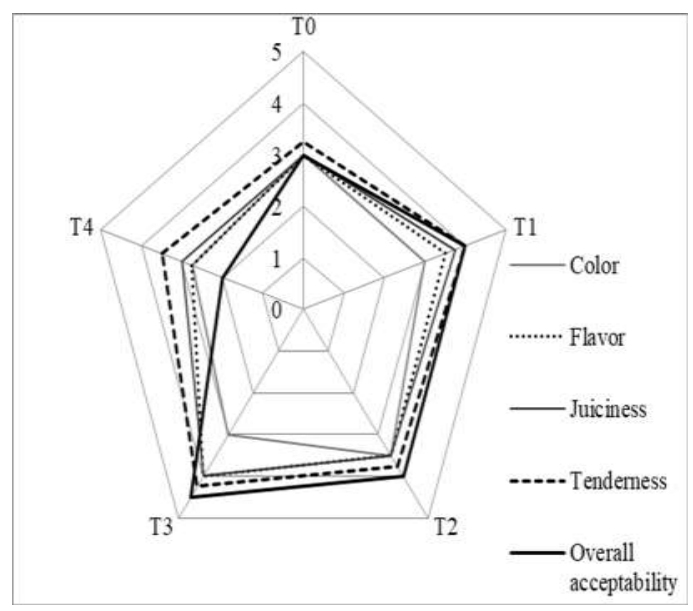

Figure 1: Sensory evaluation of broiler meat in different treatments group

Where, $T_{0}$ - No supplementation in drinking water, $\mathrm{T}_{1}$ - Neem leaves extract supplementation (10 ppm) in drinking water, $\mathrm{T}_{2}$ - Garlic leaves extract supplementation $(10 \mathrm{ppm})$ in drinking water, $\mathrm{T}_{3}-$ Plantain extract supplementation (10 ppm) in drinking water, $\mathrm{T}_{4}$ - Quinosol $10 \%$ supplementation $(10 \mathrm{ppm})$ in drinking water

\section{Sensory parameters}

The quality attributes in terms of meat sensory parameters were better in herbal supplemented group (Figure 1) over control and AGP group. This indicated that the supply of herbal extracts improved the sensory qualities of meat. Plantain treated groups exhibited best sensory qualities. Sensory properties of meat are very important in judging the quality of meat. Once the meat is bought, cooked, and served, the aroma, tenderness, juiciness, and flavor must meet the expectations (Aberle et al., 2001). Feed for animal have an important effect on this parameter. When animal is slaughtered oxidation started and antioxidant can stop this oxidation. Oxidation also deteriorates the color and flavor of meat, but if antioxidant rich feed is supplied sufficiently, it will helpful for preserving the quality of meat. All herbal extracts used in this experiment contained higher bioactive components that served as natural antioxidant in biological system and prevented oxidative rancidity of meat. And for this reason, the meat of herbal supplemented group appeared better overall acceptability than AGP and control group.

\section{Conclusion}

It may be concluded that the herbal supplements tested in this feeding trial are able to enhance growth and lean meat production in broilers avoiding dependence on antibiotic growth promoter.

\section{Acknowledgement}

The authors are grateful to University Grant Commission (UGC), Bangladesh for financing this piece of research work by providing grant to $2017 / 222 / A U-G C$ project.

\section{Conflict of interest}

The authors would like to declare that there is no conflict of interest

\section{References}

Aberle ED, JC Forrest, DE Gerrard and EW Mills (2001). Principles of Meat Science. 4th ed. Kendall/Hunt Publ. Co., Dubuque, IA.

Ahmad S (2005). Comparative efficiency of garlic, turmeric and kalongi as growth promoter in broiler. MS Thesis, Department Poultry Sciences, University of Agriculture, Faisalabad, Pakistan

Al-Mamun M, D Abe, H Kofujita, Y Tamura and $\mathrm{H}$ Sano (2008a). Comparison of the bioactive components of the ecotypes and cultivars of plantain (Plantago lanceolata L.) herbs. Animal Science Journal 9(1):83-88.

Al-Mamun M, T Yamaki, Y Masumizu, K Nakai, H Sano and Y Tamara (2008b). Anticarcinogens in Nutrition, Health and Disease, the Royal Society of Chemistry, UK, pp. 178- 187.

Al-Mamun M, D Abe, H Kofujita, Y Tamura and $\mathrm{H}$ Sano (2007). Comparison of the bioactive components of the ecotypes and cultivars of plantain (Plantago lanceolata L.) herbs. Journal of Animal Science 20:273-280.

AOAC International (1995). Official methods of analysis of AOAC International. 16th edition. 
Camy et al. (2019) Bang. J. Anim. Sci. 48 (2):108-115

Arlington, VA, USA, Association of Analytical Communities.

Aouadi R, A Aouidet, A Elkadhi, MC Rayana, H Jaafoura, B Tritar and K Nagati (2000). Effect of garlic (Allium sativum) on lipid metabolism in male rats. Nutrition Research 20:273-280.

Barton MD (2000). Antibiotic use in animal feed and its impact on human health. Nutrition Research Review 13:1-22.

Bogaard VD and EE Stobberingh (1999). Antibiotic usage in animals. Drugs 58:589-607.

Cervantes H (2004). Why responsible antibiotic use enhances animal and human health. Proceedings of Midwest Poultry Federation Convention. pp 201-210.

Chacrabati R, R Chowdhury, S Yesmin, H Sano and M Al-Mamun (2013). Comparison of broiler performance using Plantain (Plantago lanceolata L.), Bio-Sel-E and commercial diet. Bangladesh Journal of Animal Science 42:123130.

Choi H, WY Park and YJ Kim (2010). Effects of dietary garlic powder and a-tocopherol supplementation on performance, serum cholesterol levels and meat quality of chicken. Poultry Science 89:1724-31.

Choudhary RK and PL Swarnkar (2011). Antioxidant activity of phenolic and flavonoid compounds in some medicinal plants of India. Natural Product Research 25(11):1101-1109.

Chowdhury SR, SD Chowdhury and TK Smith (2002). Effects of dietary garlic on cholesterol metabolism in laying hens. Poultry Science 81: 1856-1862.

Dey B, SD Chowdhury, SM Bulbul and BLD Chowdhury (2012). Efficacy of neem leaf meal as a hypocholesterolemic dietary additive in laying pullets. Bangladesh Journal of Animal Science 40(1-2):13-17.

Etxeberria U, Fernández-Quintela A, Milagro FI, Aguirre L, Martínez JA and Portillo MP (2013). Impact of polyphenols and polyphenol-rich dietary sources on gut microbiota composition. Journal of Agricultural and Food Chemistry 61: 9517-9533.

Gold HS and RC Moellering (1996). Antimicrobial drug resistance. New England Journal of Medicine 335:1445-1453.

Gordon NC and DW Wareham (2010). Antimicrobial activity of the green tea polyphenol epigallocatechin-3-gallate (EGCG) against clinical isolates of Stenotrophomonas maltophilia. The International Journal of Antimicrobial Agents 36:129-131

Grela ER and R Klebaniuk (2007). Chemical composition of garlic preparation and its utilization in piglet diets. Veterinary Medicine 63(7): 792-795.
Ihsan, $\mathrm{K}$ (2003). Effect of different levels of kalongi ( $N$. sativa) seeds on the performance of broilers. MS Thesis, Department of Poultry Sciences, University of Agriculture, Faisalabad, Pakistan

Issa KJ and JMA Omar (2012). Effect of garlic powder on performance and lipid profile of broilers. Open Journal of Animal Sciences 2:62-68.

Javandel F, B Navidshad, J Seifdavati, GH Pourrahimi and S Baniyaghoub (2008). The favorite dosage of garlic meal as a feed additive in broiler chickens ratios. Pakistan Journal of Biological Sciences 11:1746-1749.

Konjufca VH, GM Pesti and RI Bakalli (1997). Modulation of cholesterol levels in broiler meat by dietary garlic and copper. Poultry Science 76:1264-1271.

MAFF (1998). A review of antimicrobial resistance in the food chain. A Technical Report for the UK Ministry of Agriculture, Food and Fisheries.

Marchesan M, DH Paper, S Hose and G Franz (1998). Investigation of the anti-inflammatory activity of liquid extracts of Plantago lanceolate L. Phytotherapy Research 12:S33S34.

Martins N, S Petropoulos and IC Ferreira (2016) Chemical composition and bioactive compounds of garlic (Allium sativum L.) as affected by pre- and post-harvest conditions: A review. Food Chemistry 211:41-50.

Meraj ICA (1998). Effect of garlic and neem leaves supplementation on the performance of broiler chickens. M.Sc. Thesis, Department of Poultry Sciences, University of Agriculture, Faisalabad, Pakistan.

Miles RD, GD Butcher, PR Henry and RC Littell (2006). Effect of antibiotic growth promoters on broiler performance, intestinal growth parameters, and quantitative morphology. Poultry Science 85(3):476-485

Onibi EG, EO Adebisi, NA Fajemisin and VA Adetunji (2009). Response of broiler chickens in terms of performance and meat quality to garlic (Allium sativum) supplementation. African Journal of Agricultural Research 4: 511-517.

Onu PN (2010). Evaluation of two herbal spices as feed additives for finisher broilers. Biotechnology in Animal Husbandry 26:383392.

Raeesi M, SA Hoeini-Aliabad, A Roofchaee A, ZareShahneh and Pirali S (2010). Effect of periodically use of garlic (allium sativum) powder on performance and carcass characteristics in broiler chickens. World Academy of Science, Engineering and Technology 68:1213-1219

Rahimi S, KS Azad and MAKTorshizi (2011). Omega3 enrichment of broiler meat by using 


\section{Herbal extracts in broiler production}

two oil seeds. Journal of Agricultural Science and Technology 13:353-365.

Rerksuppaphol S, W Hardikar, P Midolo and P Ward (2003). Antimicrobial resistance in Helicobacter pylori isolates from children. Journal of Paediatrics and Child Health 39: 332-335.

Roe MT and SD Pillai (2003). Monitoring and identifying antibiotic resistance mechanisms in bacteria. Poultry Science 82:622-626.

Salyers AA and CF Amábile-Cuevas (1997). Why are antibiotic resistance genes so resistant to elimination? Antimicrobial Agents and Chemotherapy 41(11):2321-2325.

Sarker SK, M Mostofa, F Akter, MM Rahman and MR Sultan (2014). Effects of aqueous extract of Neem (Azadirachta indica) leaves as growth promoter and anti-colibacillosis in broilers. Bangladesh Journal of Animal Science 43(2): 138-141.

Sultana B, F Anwar, and R Przybylski (2007) Antioxidant activity of phenolic components present in barks of Azadirachta indica, Terminalia arjuna. Acacianilotica, and Eugenia jambolana Lam. Trees, Food Chemistry. 104: 1106-1114

Swann MM, KL Baxter and HI Field (1969). Report of the Joint Committee on the use of Antibiotics in Animal Husbandry and Veterinary Medicine. Published by HMSO; London

Thampi N and VS Jeyadoss (2015). Comparative investigation of total antioxidant and free radical scavenging activities of two allium species. The Asian Journal of Pharmaceutical and clinical research 8(4):148-151.

Thomke S and $\mathrm{K}$ Elwinger (1998). Growth promoting in feeding pigs and poultry $\mathrm{ii}$; mode of action of antibiotic growth promotants. Annales de Zootechnie 47:153-167.

Wang P, J Kang, R Zheng, Z Yang, J Lu, J Gao and $Z$ Jia (1996). Scavenging effects of phenylpropanoid glycosides from leaves extract and their antibacterial activity. International Journal of Pharmaceutical Research 8(3):426-433.

Wankar AK, RN Shirbhate, KB Bahiram, SA Dhenge and RA Jasutkar (2009). Effect of Neem (Azadirachta Indica) leaf powder supplementation on growth in broilers. Veterinary World 2(10):396-397

WHO (1998). The use of quinolones in food animals and potential impact on human health. Report of a WHO meeting Geneva, Switzerland, June 1998.

Yang Q, M Qi and Tong R (2017). Plantago asiatica L. seed extract improves lipid accumulation and hyperglycemia in high-fat diet-induced obese mice. International Journal of Molecular Sciences 18(7):1393-1398.

Yeh YY and L Liu (2001). Cholesterol lowering effect of garlic extracts and organosulfur compounds: Human and animal studies. Journal of Nutrition 131: 989-993.

Zhao S, AR Datta, S Friedman, RD Walker and DG White (2003). Antimicrobial resistant Salmonella serovars isolated from imported foods. International Journal of Food Microbiology 84:87-92. 